\title{
Francesca M. Kerton and Ning Yan (Eds): Fuels, Chemicals, and Materials from the Oceans and Aquatic Sources
}

\author{
Edward R. Adlard ${ }^{1}$
}

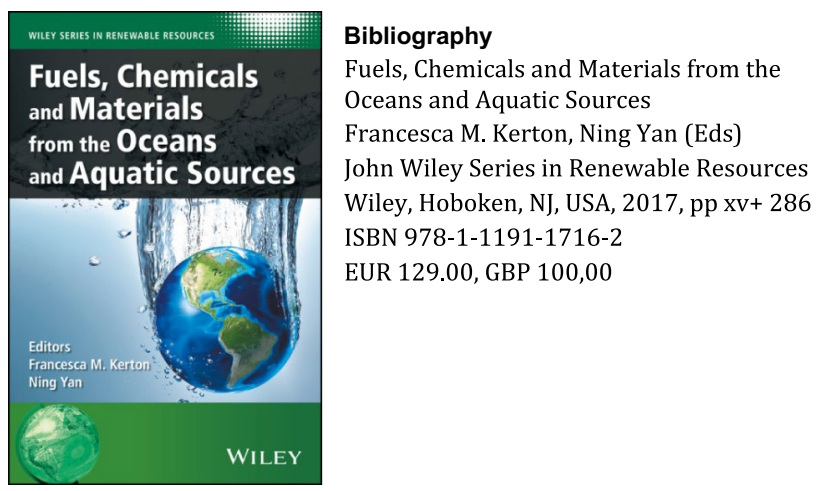

This multi-author book contains contributions from workers in Canada, India, Japan, Portugal, Singapore, China, and the USA - a truly international collection. The one thing that most of them have in common is that they are based close to some of the world's great oceans. The oceans make up $71 \%$ of the world's surface area and they represent a source of valuable materials (in addition to fish for food). Until reading this book, I would never have considered the number of useful compounds that can be isolated from such unpromising sources as mollusc shells and fish processing by-products. The topics dealt with cover a range of disparate subjects, but the title of the book is completely accurate, so at least potential purchasers should be aware of the likely contents.

The first chapter is an overview by the two editors on aquatic sources of chemicals and materials. The authors state that 6-8 million tons of waste from shellfish is produced per annum, and since currently this is of low value, it can end up being dumped and end up as a source of environmental pollution. Chitin is a valuable component of shellfish, but its recovery involves treatment with environmentally unacceptable chemicals. Improved schemes for the isolation of valuable materials are given. The next three chapters describe the isolation of a variety of products from seaweeds, but this book has shattered my youthful belief that elemental iodine was commercially obtained from seaweed. Chapter 2 describes the land-based controlled cultivation of seaweeds to produce biomass which facilitates the fixation of $\mathrm{CO}_{2}$ and yields sources of chemicals and fuels. This theme is continued in Chapters 3-5. Chapters 6 and 7 revert to the topics of the first chapter on the production of chitin and its derivatives from crustacean processing.

Chapter 8 is co-authored by one of the editors and concerns the utilization of shells which result from the commercial production of mussels. The final chapter is something of a departure from the rest of the book, since it describes the production of fuels and their properties from fish oil. These oils currently represent a useful source, although like all biooils, they are never going to replace crude oil if for no other reason that there just is not enough of them.

This is an interesting and stimulating book which describes the ongoing work in many parts of the world to make the best use of natural resources, some of which may be currently regarded as waste.
Edward R. Adlard

e.adlard77@btinternet.com

1 South Wirral, UK 